\title{
Hypovitaminosis in military services
}

\section{Durdona RAKHIMOVA ${ }^{1}$ Nilufar ASKAROVA ${ }^{2}$}

Samarkand State Medical Institute

\begin{tabular}{l} 
ARTICLE INFO \\
\hline Article history: \\
Received February 2021 \\
Received in revised form \\
20 February 2021 \\
Accepted 15 March 2021 \\
Available online \\
15 April 2021
\end{tabular}

\section{Keywords:}

hypovitaminosis, eating disorders, military personnel, proper nutrition.

\begin{abstract}
Hypovitaminosis and vitamin deficiency in general nutritional disorders of military personnel occur as concomitants, due to insufficient intake of vitamins with food, their incomplete absorption in the gastrointestinal tract, as well as insufficient absorption by the body.

Factors associated with nutrition: irregular, monotonous eating, eating a large amount of food at one time, eating dry food, hasty food, poor chewing of food, the use of a large amount of hot spices, alcohol abuse, physical fatigue, adverse environmental conditions aggravate gastrointestinal diseases path.

Correct and timely food intake, improvement of its quality, preservation of the vitamin properties of food during cooking, additional fortification of food prevents diseases of the gastrointestinal tract.
\end{abstract}

2181-1415/C 2021 in Science LLC.

This is an open access article under the Attribution 4.0 International (CC BY 4.0) license (https://creativecommons.org/licenses/by/4.0/deed.ru)

\section{Xarbiy xizmatchilarda gipovitaminoz}

\author{
Kalit so'zlari: \\ gipovitaminoz, \\ ovqatlanishning buzilishi, \\ harbiy xizmatchilar, \\ to'g'ri ovqatlanish.
}

\begin{abstract}
ANNOTATSIYA
Gipovitaminoz va vitaminlarning bo'lmasligi harbiy xizmatchilarni umumiy ovqatlanishining buzilishi, vitaminlarning oziq-ovqat bilan etarli darajada iste'mol qilinmasligi, ularning oshqozon-ichak traktida to'liq so'rilmasligi, shuningdek organizm tomonidan etarli darajada o'zlashtirilmasligi tufayli sodir bo'ladi.

Oziqlanish bilan bog'liq omillar: tartibsiz, bir xildagi ovqatlanish, bir vaqtning o'zida ko'p miqdordagi ovqat iste'mol qilish, quruq ovqat, shoshilinch ovqat, ovqatni yomon chaynash, juda ko'p ziravorlardan foydalanish, spirtli ichimliklarni ko'p
\end{abstract}

\footnotetext{
${ }^{1}$ Assistant of the Department of General Hygiene and Ecology of the Samarkand State Medical Institute, Samarkand, Uzbekistan.

2 Docent of the department "Public health and health care management" of the Samarkand State Medical Institute, Samarkand, Uzbekistan.
} 
iste'mol qilish, jismoniy charchoq, atrof-muhitning noqulay sharoitlari hisoblanadi.

Oziq-ovqat mahsulotlarini to'g'ri va o'z vaqtida qabul qilish, uning sifatini oshirish, ovqat pishirish paytida ovqatning vitamin xususiyatlarini saqlab qolish, ovqatni qo'shimcha boyitish orqali oshqozon-ichak trakti kasalliklarining oldini olish mumkin.

\section{Гиповитаминозы у военнослужащих}

\author{
Ключевые слова: \\ гиповитаминозы, \\ расстройства питания, \\ военнослужащие, \\ правильное питание.
}

\begin{abstract}
АННОТАЦИЯ
Гиповитаминозы и авитаминозы при расстройствах общего питания военнослужащих возникают как сопутствующие, вследствие недостаточного введения вместе с пищей витаминов, неполного всасывания их в желудочно-кишечном тракте, а также недостаточного усвоения их организмом.

Факторы, связанные с питанием: нерегулярное, однообразное питание, потребление большого количества пищи за один раз, еда всухомятку, поспешная еда, плохое разжевывание пищи, применение большого количества острых приправ, злоупотребление алкоголем, физическое переутомление, неблагоприятные условия внешней среды усугубляют заболевания желудочно-кишечного тракта.

Правильный и своевременный прием пищи, улучшение ее качества, сохранение витаминных свойств пищи при кулинарной обработке, дополнительная витаминизация пищи предупреждают заболевания желудочно-кишечного тракта.
\end{abstract}

Расстройства общего питания бывают первичные и вторичные.

Первичные расстройства общего питания, развиваются при несоответствии питания и энергетических трат организма (например, длительные марши в неблагоприятных метеорологических и физико-географических условиях - жара, холод, сырость), при недостаточном снабжении продуктами питания в условиях транспортных затруднений горно-пустынных местностей.

Вторичные расстройства общего питания, возникают при достаточном и полноценном питании в результате нарушения процессов всасывания и усвоения питательных веществ организмом или вследствие патологических изменений в обмене веществ (заболевания желудочно-кишечного тракта, различные хронические истощающие заболевания).

Пища должна быть богата витаминами, однако большого количества витаминов вследствие понижения у больных обменных процессов в первое время вводить не следует.

Витаминная недостаточность, обусловленная недостаточным поступлением витаминов с пищей, называется первичной, экзогенной или алиментарной. 
Витаминная недостаточность, обусловленная плохим всасыванием витаминов в кишечнике или недостаточным усвоением их называется эндогенной формой витаминной недостаточности.

Повышенная потребность в витаминах, например, при усиленной физической нагрузке, перегревании, переохлаждении, а также избыточным разрушением витаминов в организме, что бывает при различных заболеваниях, особенно инфекционных, называется относительной витаминной недостаточностью.

В основе патогенеза витаминной недостаточности лежат нарушение важнейших ассимиляторных и диссимиляторных процессов в организме. При недостатке в пище витаминов нарушается клеточное дыхание, углеводный обмен, минеральный обмен, синтез гормонов, проницаемость капилляров, всасывание и др. важнейшие физиологические функции.

По степени выраженности клинических явлений витаминной недостаточности различают формы развитые и стертые; они возникают при недостаточном содержании витаминов в организме. Стертые формы не дают яркой клинической картины и в тоже время имеют наибольшее практическое значение.

Недостаточность витамина А обусловливается недостатком или отсутствием его в пище или нарушениями превращения в организме провитамина А (каротина) в витамин А.

Дефицит витамина А в организме вызывает нарушение регенерации зрительного пурпура - родопсина, что ведет к расстройству адаптации к темноте; метаплазию покровного эпителия в различных областях, сопровождающуюся нарушением функции пораженной поверхности. Обычно поражается эпителий роговой оболочки (кератомаляции, ксерофталмия), кожи (атрофия потовых и сальных желез), верхних дыхательных путей (риниты, трахеиты, бронхиты), мочевыводящих путей (пиелиты с изменением реакции мочи и вторичным образованием мочевых камней), желудочно-кишечного канала (ахилия, поносы).

Куриная слепота (гемералопия) является самым характерным и наиболее ранним симптомом недостаточности витамина А. Больные теряют способность различать предметы ночью, а в сумерках у них отмечается значительное понижение зрения. Однако и днём у этих больных понижено светоощущение и способность к работе, требующей напряжения зрения. Нарушено также ощущение цветов, в первую очередь желтого и синего. Куриной слепоте могут предшествовать более легкие нарушения зрения, как, например, недостаточная приспособляемость к темноте, так называемая дезадаптация, которая может быть выявлена лишь при помощи специальных приборов - адаптометров. Для авитаминоза А характерно, кроме того, общая склонность эпителиальных покровов к ороговению, высыханию и шелушению. Ороговению подвергается не только кожа, но и слизистые оболочки, в первую очередь, глаз и верхних дыхательных путей. На конъюнктиве глаз появляются белесоватые или желтые пятна, покрытые сальным налетом. Слезы не смачивают их. В последующем сухость распространяется на всю конъюнктиву. Конъюнктивальный мешок уменьшается в объёме «высыхает» (ксерофтальмия), чувствительность конъюнктивы и роговицы понижается. Роговица теряет блеск, не смачивается слезной жидкостью, её эпителий мутнеет, а в тяжелых случаях появляется глубокий инфильтрат роговицы, превращающийся в язву и ведущей к распаду роговицы (кератомаляция). Кожа при авитаминозе А суха, пигментирована 
и сильно шелушится, фолликулы роговеют. Вследствие ороговения (эпидермизации) эпителия слизистой носа понижается обоняние и возникает упорный насморк. Эпидермизация гортани ведет к ларингиту и охриплости голоса. Метаплазия трахеи и бронхов - трахеиту и бронхиту. Ороговение слизистой рта и языка обусловливает сухость в углах рта, развитие стоматита. Изменения в эпителии желудка и кишечника вызывают понижение секреции вплоть до полной ахилии, развития поносов. В мочевыводящих путях повышенное слущивание измененного эпителия ведет к развитию неспецифического цистита и уретрита. В мочевыводящих путях часто образуются конкременты. Исход при куриной слепоте благоприятный, при ксерофтальмии-благоприятный в начале и сомнительный при далеко зашедшем процессе. При кератомаляции исход всегда серьезный, как в отношении восстановления функции зрения, так и в отношение жизни больного.

Основные лечебно-профилактические мероприятия при недостаточности витамина A:

- назначение пищи, богатой витамином А или провитамином-каротином. Наиболее богаты витамином А животные жиры (за исключением свиного сала);

- сливочное масло, рыбий жир, жирное мясо и рыба, молоко и молочные продукты, яйца. Значительные количества провитамина - каротина, из которого легко образуется витамин А, содержится в красной моркови, томатах, черной смородине, зеленом горошке, вишне, абрикосах;

- назначение масляного раствора каротина (содержит в 1 мл 75000 Ме; ежедневный прием 2-3 капли) и водного его раствора. Каротин дают внутрь из расчета суточной потребности в нем 3-5мг, он может применяться в виде глазных капель, для лечения ксерофталмии и кератомаляции. При назначении рыбьего жира (3 столовые ложки в день) куриная слепота устраняется в течение 1-3 суток. Более длительное применение необходимо при ксерофтальмии и особенно при керотамаляции для предупреждения заболевания рекомендуется ежедневно давать с пищей 0,5-1 мг витамина А или 3,5 мг каротина (суточная потребность в витамине А). При питании продуктами, мало содержащими витамин А или во всех его не содержащих (растительное масло, свиное сало, маргарин, мука, нежирная говядина, баранина), необходимо добавлять витамин А в виде рыбьего жира, томатного пюре или масляного раствора каротина из расчета суточной потребности.

Во многих случаях одновременно отмечается недостаток рибофлавина, витамина В1 - тиамина, а также витамина С. Решающее значение имеет недостаточное содержание витамина РP.

Дефицит никотиновой кислоты приводит к нарушению углеводного и белкового обмена, к уменьшению железа в организме и расстройству пигментного обмена с порфиринурией. Некоторые проявления пеллагры связаны с дефицитом в организме и других витаминов комплекса В (витамин В 2 рибофлавин, а также витамин $\mathrm{B}_{1}$ ).

Синдромы пеллагры могут возникать вторично, на почве нарушения всасывания никотиновой кислоты или усиленного ее разрушения у больных с хроническими заболеваниями желудочно-кишечного тракта (хроническая дизентерия, туберкулёз кишечника, протозойные заболевания, например, 
балантидиаз) или с затяжными формами других инфекционных заболеваний (затяжная форма брюшного тифа, септические состояния).

Клиническая пеллагра проявляется либо в виде отчетливо выраженного тяжелого заболевания с его основными признаками - дерматитом, диареей, деменцией (три «D»), либо в виде легких, стертых форм, так называемых пеллагроидов.

Основными изменениями при пеллагре являются изменения со стороны кожи, желудочно-кишечного тракта и нервной системы. Развитию типичных признаков предшествует длительный (1-3 месяца) продромальный период, в течение которого больные жалуются на недомогание, слабость, потеря аппетита, головокружения, бессонницу. Уже в этом периоде можно отметить бурную пигментацию на коже лица, замедленность движений, ослабление памяти. В дальнейшем на различных участках кожи, преимущественно на открытых частях тела появляются пятна (на лице, шее, на тыле кистей, стоп и разгибательных поверхностях голеней), напоминающие солнечные ожоги. Эритематозные участки приобретают коричнево бурый оттенок и шелушатся. В острых случаях на пораженной, слегка отечной коже возникают многочисленные пузыри с серозным содержимым нередко превращающиеся в гнойные пустулы. В дальнейшем измененные участки кожи рубцуются Кожа иногда истончается, делается блестящей, прозрачной («пергаментной»). Со стороны крови отмечается анемия гиперхромного типа с макро-анизопойкилоцитозом. Реакция оседания эритроцитов ускорена.

К ранним проявлениям пеллагры относятся также симптомы со стороны органов пищеварения как потеря аппетита, жжение во рту, слюнотечение, трещины у углов рта. Слизистая рта и губ ярко красные и отечные. Язык покрыт бурым налетом, иногда разделенным трещинами на поля (шахматный язык). Края и кончик языка ярко красные, иногда и весь язык становится красным, гладким и блестящим (лакированным). Одновременно с изменением языка начинаются упорные поносы, испражнения жидкие, с гнилостным запахом.Со стороны желудка отмечается ахилия и гипотония с понижением эвакуаторный способности желудка. Пульс частый, малый, артериальное кровяное давление понижено. Изменения со стороны центральной нервной системы выражаются в понижении памяти, потери ориентировки, депрессивном состоянии. Больные молчаливы, труднодоступны, безразличны к окружающему. Наблюдается расстройство всех видов чувствительности тела, шаткость походки, глазные симптомы (диплопия, птоз, расстройство аккомодации, анизокория). В более позднем периоде могут наблюдаться психозы с галлюцинаторным или депрессивным синдромом. Течение пеллагры хроническое, рецидивирующее, с обострениями и ремиссиями.

Лечебное питание является частью комплексной терапии больных военнослужащих. Оно оказывает большое влияние на обмен веществ и общее состояние организма, повышает устойчивость к болезнетворным микробам, токсическим и другим неблагоприятным воздействиям, благотворно влияет на нервную систему, улучшает общее самочувствие. Благодаря этому предотвращается развитие осложнений и хронических заболеваний, ускоряется 
заживление ран и восстановление нарушенных функций, сокращаются сроки восстановления работоспособности и боеспособности.

Витамины. Потребность военнослужащих в витаминах зависит от возраста, пола, состояния здоровья, условий внешней среды, калорийности, соотношения питательных веществ в рационе и других факторов. У лиц, труд которых не связан с физической нагрузкой, потребность в витаминах определяется следующими цифрами: витамин В1 - 1,7 мг; В2 - 2,1 - 2,2 мг; РP - 17-18 мг; В6 2 мг; С - 6570 мг; А - 1,5 мг (5000 ME).

Согласно литературным данным, важным фактором в обмене рибофлавина является свободная соляная кислота, стабилизирующая витамин В2. Известно, что в щелочной среде витамин В2, менее устойчив. Следует учитывать влияние соляной кислоты на быстроту эвакуации рибофлавина из желудка в двенадцатиперстную кишку. Постепенный переход витамина В2 из желудка в двенадцатиперстную кишку создает более благоприятные условия для меньшего его разрушения в щелочной среде. Большей кислотообразующей функции желудка соответствовала большая экскреция рибофлавина. Это подтверждает необходимость усиленного насыщения рибофлавином больных с преимущественно пониженной кислотообразующей функцией желудка. Назначение указанного витамина больным целесообразно сочетать с желудочным соком. Экскреция водорастворимых витаминов у здоровых и больных с хроническими заболеваниями органов пищеварения, находящимися в условиях жаркого климата, следует отметить более выраженный дефицит экскреции этих витаминов у больных. Можно полагать, что большая степень дефицита экскреции рибофлавина и тиамина у больных обусловлена влиянием, с одной стороны, нарушенных функций органов пищеварения, с другойпредшествующим дефицитом витаминов в организме, связанным с воздействием условий внешней среды и характером пищевого статуса.

Повышенная потребность в ряде витаминов установлена при ранениях, ожоговой и лучевой болезнях, лихорадочных состояниях, инфекционных заболеваниях, интоксикациях, при лечении больных сульфаниламидами и антибиотиками, при состояниях высокого физиологического напряжения (стрессе).

Трудности в обеспечении витаминами обусловлены прежде всего повышенной потребностью организма при различных патологических состояниях. Обеспеченность витаминами снижается и при неполном потреблении рациона, нарушении правил кулинарной обработки пищевых продуктов и хранения готовой пищи. Отсюда необходимость в систематическом контроле за обеспеченностью раненых и больных витаминами. Если потребность в витаминах заведомо повышена, например, при лучевых поражениях, лечении антибиотиками, сульфаниламидами и в других случаях, раненым и больным целесообразно выдавать поливитаминные препараты.

Минеральные вещества входят в состав костной ткани, мышц, тканевых жидкостей, ряда гормонов и ферментов, участвуют в окислительновосстановительных процессах, кроветворении, поддержании кислотно-щелочного равновесия, осмотического давления в тканях и регуляции водно-солевого обмена.

Нарушения минерального, в частности, электролитного обмена, играют важную роль в развитии ряда патологических состояний. Причиной подобных нарушений может быть недостаточное поступление отдельных минеральных 
веществ с пищей, плохая усвояемость и повышенная потребность в них, потеря минеральных веществ с раневым отделяемым, рвотными массами, нарушение баланса отдельных минеральных элементов из-за сдвигов в обмене веществ.

Кальций оказывает благотворное влияние на заживление ран и костных переломов, течение воспалительных процессов. Точная потребность в кальции равна 0,8-1,0 г. Необходимо, чтобы раненые или больные получали его в достаточных количествах.

Ограничение количества натрия в пище оказывается целесообразным в тех случаях, когда необходимо устранить задержку воды в тканях или уменьшить нагрузку на почки, через которые натрий (в виде хлористого натрия) выводится из организма. Установлено, что 10-15г соли способны задержать в организме 1,5-2 л жидкости. Ограничение поваренной соли в диете оказывается полезным при нефритах и нефрозах, гипертонической болезни, при травме черепа, эпилепсии и эклампсии, для уменьшения гидратации головного мозга, при ревматизме, бронхоэктатической болезни, гангрене, эмпиеме, недостаточности кровообращения, асцитах. Уменьшение количества натрия в диете оказывает и противовоспалительное действие.

К пищевым продуктам с повышенным содержанием хлористого натрия можно отнести картофель, капусту, свеклу, морковь и фрукты, Хлеб также богат поваренной солью, белый содержит 7-8 г соли на 1 кг, а ржаной - значительно больше.

Пищу по бессолевой диете готовят без добавления поваренной соли. Соль выдают больным на руки в количестве 2-3 г.

В рационе большинства людей содержится 10-12 г поваренной соли, из них 5-7 г добавляются при приеме пищи. Количество хлористого натрия в пище может повышаться до 15-20 г и более, особенно при увеличении потребности в нем вследствие повышенных потерь.

Натрий и калий. Нарушение обмена натрия и калия может вести к небезразличным для организма сдвигам в электролитном и водном балансе тканей.

Длительное нахождение на бессолевой диете может привести к обеднению организма хлоридами и вследствие этого к слабости, снижению аппетита, рвоте, поносу и другим расстройствам. Поэтому периодически необходимо назначать диету, содержащую до 5 г поваренной соли. При строгом ограничении хлористого натрия организм получает около 1,5 г соли с пищей.

Калий является антагонистом натрия. Потребление его в повышенном количестве усиливает диурез, выведение натрия и потерю жидкости. Много калия содержит картофель, бобовые (соя, фасоль), курага. Потребность в нем равна 2-3 г.

Железо. Входит в состав гемоглобина, миоглобина и дыхательных ферментов - цитохромов. Потребность в нем повышается при кровопотерях, плохом усвоении его, например, в случаях ахилии.

Контроль за питанием предусматривает оценку минерального состава пищи, приготовляемой по различным лечебным диетам, и при необходимости внесение в него корректив. Особое внимание следует обращать на использование пищевых продуктов, богатых кальцием (молоко и молочные продукты) и железом (мясо, печень, почки, язык, бобы, капуста цветная, свекла). 
При осуществлении контроля за питанием необходимо иметь в виду, что обеспеченность организма белками, витаминами, минеральными солями зависит не только от содержания этих веществ в рационе, но и от уровня потребления пищи. У раненых и больных, находящихся на постельном режиме, снижается расход энергии, падает аппетит, увеличиваются остатки несъеденной пищи, хлеба. Естественно, что и поступление в организм ряда питательных веществ уменьшается. Поэтому при контроле за качественной полноценностью питания необходимо учитывать уровень фактического потребления пищи.

\section{ВЫВОдЫ:}

У здоровых военнослужащих в жарком климате отмечается выраженная зависимость обмена водорастворимых витаминов от условий прямого воздействия климатических факторов. У лиц, находящихся в закрытых помещениях со сравнительно невысокой температурой внешней среды (до 280 C), эти изменения выражены в значительно меньшей степени.

Для предупреждения расстройства общего питания необходимо постоянно контролировать калорийность и полноценность питания солдатов и офицеров (содержания белков, жиров, углеводов, минеральных солей и витаминов), проверять, соответствует ли питание энергетическим тратам организма, выявлять лиц с начальными проявлениями расстройства общего питания во время профилактических медицинских осмотров личного состава воинской части, систематически наблюдать за физически ослабленными военнослужащими.

Витамина А обеспечивается подачей масла, сгущенного молока, зелени, сухофруктов, витамина комплекса В - дачей ржаного хлеба, гречневой каши, свежего мяса. Необходимая суточная доза витамина РР составляет 20-25 мг, витамина В1-2 мг. Витамин С содержится в овощах, его следует давать ежедневно по 50 мг. Витамин Д содержится в масле, молоке. С пользой может быть применен настой шиповника и хвои, отрубей и пекарских дрожжей.

\section{БИБЛИОГРАФИЧЕСКИЕ ССЫЛКИ}

1. Авцын А.П. Микроэлементозы человека: этиология, классификация, органопатология / А.П. Авцын, А.А. Жаворонков, М.А. Риш. - М.: Медицина. 1991. - С. 496.

2. Агаджанян Н.А. Эколого-биогеохимические факторы и здоровье человека / Н.А. Агаджанян, В.Л. Сусликов, Н.В. Ермакова // Экология человека. - 2000. - № 1. C. 3-5.

3. Аничков Н.М. Патофизиология обмена веществ / Н.М. Аничков, А.В Дергунов, В.Н. Цыган - СПб., 2013. - С. 335.

4. Арнольди И.А. Акклиматизация человека на севере и юге / И.А. Арнольди. М.: Медгиз, 1962. - С. 72.

5. Бабенко Г.А. Микроэлементозы человека: патогенез, профилактика, лечение / Г.А. Бабенко // Микроэлементы в медицине. - 2001. - Т.2, № 1 - С. 2-5.

6. Баранов А.А. Природный дефицит микроэлементов и пути его преодоления / А.А. Баранов, Л.А. Щепягина, Л.И. Васечкина // Вестн. РАМН. 2001. - № 6 - C. 21-25. 
7. Беневоленская Л.И. Остеопороз: клинические рекомендации / Л.И. Беневоленская, Н.В. Торопцова, О.А. Никитинская // Лечащий врач. - 2006. № $10 .-$ С. 50-53.

8. Боев В.М. Микроэлементы и доказательная медицина / В.М. Боев. М.: Медицина, 2005. - С. 208.

9. Воложин А.И. Остеопороз / А.И. Воложин, В.С. Оганов. - М.: Практ. медицина, 2005. - С. 238.

10. Вялков А.И. Основные задачи Международной Декады (The Bone and Joint Decade 2000-2010) в совершенствовании борьбы с наиболее распространенными заболеваниями опорно-двигательного аппарата в России / А.И. Вялков, Е.И. Гусев, А.Б. Зборовский, В.А. Насонова // Науч.практ. ревматология. - 2001. - № 2. C. 4-15.81.

11. Горбачев А.Л. Основы биоэлементологии / А.Л. Горбачев, Е.А. Луговая, А.П. Бульбан. - Магадан: СВГУ, 2007. - С. 73.

12. Горбачев А.Л. Проблемная статья особенности микроэлементного статуса пожилых и старых людей / А.Л. Горбачев, А.В.Скальный // Микроэлементы в медицине. - 2009. - Т. 10, № 1/2. - С. 17-26.

13. Государственная программа «Социально-экономическое развитие Арктической зоны Российской Федерации на период до 2020 года» / Постановление Правительства РФ от 21.04.2014 г. № 366 [Электронный ресурс] // Режим доступа: Сайт Правительства РФ.

14. Деряпа Н.Р. Адаптация человека в полярных районах Земли / Н.Р. Деряпа. - Л.: Медицина, 1977. - С. 160.

15. Доршакова Н.В. Качество окружающей среды и здоровье человека в условиях Карелии / Н.В. Доршакова. - Петрозаводск: ПетрГУ, 1997. - С. 204.

16. Егоров А.И. Перспективы использования дистиллята термических опреснителей в хозяйственно-питьевом водоснабжении / А.И. Егоров, П.Ф. Ипатов, И.Г. Вахнин // Химия и технология воды. - 1984. - Т. - 6, № 3. - С. 274- 276.

17. Ибрагимова М.Я. Взаимосвязь дисбаланса макро-и микроэлементов и здоровье населения: обзор лит. / М.Я. Ибрагимова, Л.Я. Сабирова, Е.С. Березкина [и др.] // Казан. мед. журн. - 2011. - Т. 92, № 4. - С. 606-609.

18. Иванов С.И. Определение химических элементов в биологических средах и препаратах методами атомно-эмиссионной спектрометрии с индуктивно связанной плазмой и масс-спектрометрией: методические указания (МУК 4.1.1482-03, МУК 4.1.1483-03) / С.И. Иванов, Л.Г. Подунова, В.Б. Скачков [и др.]. - М.: Федер. Центр Госсанэпиднадзора М-ва России, 2003. - С. 56.

19. Игнатьев Ю.Т. Отдаленные последствия компрессионных переломов тел позвонков у детей / Ю.Т. Игнатьев // Детская хирургия. - 2004. - №4. - С. 22-27. 82.

20. Казначеев В.П. Биосистема и адаптация / В.П. Казначеев. - Новосибирск: Сов. Сибирь, 1993. - С. 76.

21. Aaseth J. Osteoporosis and trace elements-an overview / J. Aaseth, G. Boivin, 0. Andersen // J. Trace Elem. Med. Biol. - 2012. - Vol. 26, № 2. - P. 149-152.

22. Adams J.S. Update in vitamin D / J.S Adams, M. Hewison // J. Clin. Endocrinol. Metab. - 2010. - Vol. 95, № 2. - P. 471-478.

23. Albright F., Postmenopausal osteoporosis: its clinical features / F. Albright, P.H. Smith, A.M. Richardson // JAMA. - 1941. - Vol. 116, №. 22. - P. 2465-2474. 
24. Allain T.J. Thyroid hormones and bone / T.J. Allain, A.M. McGregor // J. Endocrinol. - 1993. - Vol. 139, № 1. - P. 9-18.

25. Andersen R. Teenage girls and elderly women living in northern Europe have low winter vitamin D status / R. Andersen, C. Molgaard, L.T. Skovgaard [et al.] // Eur. J. Clin. Nutr. - 2005. - Vol. 59, № 4. P. 533-541.

26. Angeli A. High prevalence of asymptomatic vertebral fractures in postmenopausal women receiving chronic glucocorticoid therapy: a cross-sectional outpatient study / A. Angeli, G. Guglielmi, A. Dovio [et al.] // Bone - 2006. - Vol. 39, № 2. P. 253-259.

27. Aubin J.E. Osteoprotegerin and its ligand: a new paradigm for regulation of osteoclastogenesis and bone resorption / J.E. Aubin, E. Bonnelye // Osteoporosis Int. 2000. - Vol. 11, № 11. - P. 905-913.

28. Bachman D.M. Comparison of heel ultrasound and finger DXA to central DXA in the detection of osteoporosis. Implications for patient management / D.M. Bachman, P.E. Crewson, R.S. Lewis // J. Clin. Densitom. - 2002, Vol 5, № 2 - P. 131-141.

29. Bala Y. Bone mineralization: from tissue to crystal in normal and pathological contexts / Y. Bala, D. Farlay, G. Boivin // Osteoporosis Int. - 2013. - Vol. 24, № 8. P. 2153-2166. 86.

30. Bala Y. Respective roles of organic and mineral components of human cortical bone matrix in micromechanical behavior: an instrumented study / Y. Bala, B. Depalle, T. Douillard [et al.] // J. Mech. Behav. Biomed. Mater. - 2011. - Vol. 4. № 7. - P. 1473-1482. 